\title{
"A EDUCAÇÃO PRECISA DE RESPOSTAS" OU AS RESPOSTAS ESTÃO NA EDUCAÇÃO? REPRESENTAÇÃO E (RE)SIGNIFICAÇÃO NA CAMPANHA DOS MONSTRINHOS DA RBS*
}

\author{
Gislene Feiten Haubrich \\ Universidade Feevale, Novo Hamburgo, Rio Grande do Sul, Brasil \\ ERnani Cesar de Freitas \\ Universidade Feevale, Novo Hamburgo, Rio Grande do Sul, Brasil
}

\begin{abstract}
Resumo: Pensar a educação implica aproximação com as realidades construídas pelos sujeitos em suas interações. Relacionada a essa questão, está a ação midiática, que produz e repercute informações a partir dos acontecimentos do cotidiano. Unem-se essas perspectivas, pois ambas assumem evidência na formação da opinião cidadã. Dado esse contexto, a partir da campanha "A Educação precisa de Respostas", propõe-se a análise do discurso da mídia sobre a educação, a fim de perceber como esta é representada e (re)significada. O marco teórico é composto por Hall (1997), Morin (2009) e Charaudeau (2012). Como resultados principais, acredita-se que a campanha tenha relevância social por despertar o interesse à temática, mas o faz de forma parcial frente os desafios da educação na contemporaneidade.
\end{abstract}

Palavras-chave: Mídia. Educação. Campanha RBS. Análise do discurso.

INTRODUÇÃO

A proposta de investigar as temáticas educação e mídia não alude a uma tarefa fácil, mas o oposto; refere-se a uma discussão tomada por curvas, ramificações, cruzamentos e conjunções. Trata-se, porém, de uma reflexão fundamental, principalmente na contemporaneidade, período marcado por muitos aspectos negativos quanto à (re)construção das relações humanas

\footnotetext{
* Artigo recebido em 6/3/2014 e aprovado em 10/6/2014.
} 
(BAUMAN, 2007; LIPOVETSKY, 2007; SENNETT, 2009). Nesse sentido, ponderase que as percepções acerca do encontro das noções de mídia e educação precisam ser mediadas com cautela, a fim de desenvolverem-se na amplitude que evite juízos de valor e o estabelecimento de posições binárias, como a definição de inocentes e culpados.

A interface mídia-educação pode ser ancorada em múltiplos olhares. Neste estudo, privilegia-se o contemplar da educação a partir de sua projeção na mídia, efetiva mobilizadora comportamental. Acredita-se que as representações construídas a partir de campanhas de grupos de mídia tenham potencial de cristalizar determinados elementos, devido a sua ampla abrangência, além da simplificação e reducionismo no tratamento das temáticas que se propõe, uma vez que a lógica mercadológica impõe um ritmo alucinado às projeções de impactos midiáticos diários a cada sujeito. Esse contexto justifica a seleção do objeto de pesquisa - a campanha “A Educação precisa de Respostas" -, encabeçada pelo grupo RBS.

Justifica-se, ainda, a escolha do objeto, uma vez que se trata de uma abordagem cuja ênfase midiática apoia-se em elementos da cultura popular, que promove aproximação simbólica tanto de adultos quanto de crianças, o que garantiu o engajamento social à temática proposta pela campanha. Salienta-se que o estudo é relevante diante da reduzida produção acadêmica na ótica proposta.

Dentre os diversos materiais que compõem a campanha, elege-se como corpus de análise deste artigo os quatro anúncios principais veiculados em diversos jornais impressos do grupo. Defende-se esse recorte porque tais materiais sintetizam as concepções centrais da campanha e repercutem os elementos visuais do pilar publicitário, ponto em que se pode perceber maior sensibilização da audiência pública à proposta do grupo midiático.

À luz desses aspectos e a partir da interface entre noções relacionadas à educação e mídia, chega-se à problemática que mobiliza este estudo: Como a noção de educação é representada e (re)significada na campanha "A Educação precisa de Respostas", elaborada pelo grupo de mídia RBS? Supõe-se que a campanha não atenda às demandas reais da sociedade contemporânea, uma vez que se vale da repetição de elementos à construção simbólica e percebe a educação como uma ferramenta a favor do conhecimento científico, o que não parece adequado frente aos desafios de uma coletividade complexa e com uma ampla diversidade cultural.

Para responder à questão proposta, o artigo tem como objetivo identificar e analisar os elementos utilizados para representação e (re) significação da noção de educação na campanha publicitária selecionada, a fim de descrever possíveis interpretativos diante dessa situação de 
comunicação. Para tanto, visa-se a apropriação de possibilidades teóricas que respaldem a percepção da mundialização e da ação midiática em interface a reflexões acerca da educação.

Quanto aos procedimentos metodológicos, trata-se de uma pesquisa de natureza aplicada e abordagem qualitativa, visto que se utiliza de um corpus específico para a observação do fenômeno em análise. Tem caráter exploratório, pois implica a interface entre conceitos das áreas da educação e comunicação, e seu emprego à situação selecionada. Possui ainda objetivos descritivos frente à metodologia de análise selecionada, a análise do discurso francesa de Patrick Charaudeau. Para coleta de dados, aciona-se a pesquisa bibliográfica e documental, diante do acesso aos anúncios que compõem o objeto escolhido. Acredita-se que essas técnicas conduzirão ao encontro de respostas ao problema de pesquisa proposto.

Para atender à dinâmica proposta neste estudo, acredita-se, é fundamental buscar olhares que contemplem a diversidade e complexidade das relações sociais na contemporaneidade. À luz dessa guia, compõe-se o marco teórico. Do olhar de Hall (1997), que privilegia as formas de construção de significação diante das representações construídas através do discurso, às reflexões acerca da educação, que decorrem de Morin (2009), Pimenta e Anastasiou (2010) e Carnoy (2002). A teoria semiolinguística de Charaudeau $(2010,2012)$ sustenta a metodologia de análise do discurso midiático escoIhido. $\mathrm{O}$ artigo é dividido em três blocos, sendo dois teóricos e um de análise.

\section{UM OLHAR DA CULTURA PARA A CULTURA: (RE)SIGNIFICAÇÃO DOS OLHARES À EDUCAÇÃO?}

Os recentes relatórios divulgados com dados acerca da realidade educacional brasileira, ou mesmo a mundial, não são animadores. Embora o Censo Escolar de 2012 assinale como positivos os resultados acerca das matrículas no ensino das séries iniciais, diante das políticas públicas de adequação idade-série, o levantamento da Unesco $(2014$, p. 3) aponta que "um terço das crianças em idade de cursar a educação primária não está aprendendo o básico, estejam ou não na escola." Esses dados complementam o levantamento feito por Carnoy (2002), no qual fica evidente que a reforma do sistema de educação está focada na competitividade, característica da contemporaneidade, vide os elementos de avaliação da qualidade do ensino que enfatizam os níveis de aprendizado em prol de uma classificação que conduz a seleção dos indivíduos aos diversos coletivos que compõem a sociedade. Essa visão que segrega uns dos outros mostra que a educação 
tem sido percebida como "bem de consumo, um meio para a sobrevivência financeira e social" (PIMENTA; ANASTASIOU, 2010, p. 95).

O levantamento de Carnoy (2002, p. 107), publicado pela Unesco, aponta ainda os reflexos da mundialização na educação. "Ela está focalizada no conhecimento; no entanto, os mercados mundiais enfatizam determinado tipo de conhecimento em detrimento de outros." Esse aspecto pode ser observado nos dados do relatório do CNI-IBOPE (2010, p. 16), diante da afirmação de que "na percepção da sociedade, a escola precisa dar mais ênfase no ensino de disciplinas essenciais, como português e matemática. Concordam totalmente ou em parte com essa afirmação $68 \%$ dos brasileiros", além de oferecer"mais cursos profissionalizantes em conjunto com o ensino médio." Embora se compreenda que tais disciplinas sejam basilares ao estabelecimento do que são considerados, ainda hoje, estudos científicos de qualidade, ou seja, passíveis de provas exatas, há um movimento que enfatiza os malefícios de tantos anos desse "pensamento que cega" (MORIN, 2009).

Hall (2006) observa as transformações ao logo do tempo na relação sujeito - mundo, do homem do iluminismo ao homem pós-moderno, cujos movimentos estruturam um conceito diferenciado da mundialização. Tempo e espaço assumem novos conceitos e a flexibilidade passa a ser seu norte. As relações estabelecidas entre diferentes formas de condutas sociais, a cultura, implicam atualizações de sentido frente às situações vivenciadas (HALL, 2006). Por esses aspectos, Hall (1997) defende que na contemporaneidade é necessário transcender as explicações econômicas e produzir um olhar que contemple os elementos simbólicos na tomada de decisões.

Hall (1997, on-line) refere-se à "expansão substantiva da cultura sua crescente centralidade nos processos globais de formação e mudança, sua penetração na vida cotidiana e seu papel constitutivo e localizado na formação de identidades e subjetividades." Acredita-se que essa perspectiva deva também permear o ambiente escolar, já que "é dever da escola conduzir o aluno a um processo de desconstrução e construção da realidade" (RIBEIRO, 2009, p. 48), a fim de que promova uma formação adequada à resolução dos problemas sociais deste tempo, sendo o principal, segundo Bauman (2014), a superação do individualismo e a retomada da esperança no futuro.

\section{DISCURSOS MIDIÁTICOS: REPRESENTAÇÃO DA EDUCAÇÃO EM TEMPOS DE MUNDIALIZAÇÃO}

Segundo Pimenta e Anastasiou (2010, p. 98), "identificada como uma instituição que transmite informações, a escola tende a desaparecer, porque não tem a eficácia dos meios de comunicação nesse processo". A crítica dos 
autores refere-se ao uso inadequado da tecnologia na sala de aula, que implica tanto consequências aos alunos postos a uma mera transferência de dados, por vezes desconexos, quanto à mudança na identidade dos docentes, que passam a ser menos valorizados por suas práticas pedagógicas diferenciadas e desmotivam-se por terem sua atuação reduzida à mediação entre as máquinas e os alunos, os quais passam a ser plenamente responsáveis por seu processo de aprendizagem. Esses sujeitos não chegam a desenvolver, então, qualificações que permitam uma leitura crítica dos eventos cotidianos (CALDAS, 2006), como os veiculados pela mídia, e passam a reproduzir modelos reducionistas da realidade, repercutidas no mercado de trabalho, o qual exige cada vez mais elementos identitários, como iniciativa, criação e inovação.

Nesse sentido, Caldas (2006, p. 118) defende uma integração entre os campos da educação e comunicação com a finalidade de buscar "resultados mais eficazes nos procedimentos pedagógicos das escolas", uma vez que "os meios de comunicação interferem diretamente na formação/deformação das pessoas, sejam elas crianças, jovens ou adultos". Essa integração, acredita-se, deve refletir o que Morin (2009) denomina de "reforma do pensamento". Se as modalidades tradicionais de transmissão de informações têm implicado as consequências apontadas anteriormente, fica evidente a necessidade de um salto no processo educacional, o que tende a significar o atendimento a "uma necessidade social-chave: formar cidadãos capazes de enfrentar os problemas de seu tempo" (MORIN, 2009, p. 26), o tempo de uma sociedade mundializada.

A integração entre educação e comunicação proposta neste estudo não se refere ao uso direto das tecnologias em sala de aula, mas à reflexão acerca dos impactos de campanhas cujo propósito é pensar acerca do sistema educacional vigente. Globalmente, a Unesco propôs, no ano 2000, o programa “Educação Para Todos (EPT, 2000-2015)", cujos objetivos centram-se na inclusão plena dos sujeitos à educação básica e na melhoria da qualidade das práticas de ensino-aprendizagem. O último relatório não é otimista quanto ao atendimento das metas propostas: "o relatório deixa claro que não" (UNESCO, 2014, p. 3). Salienta-se o entendimento desenvolvido à noção de educação no referido relatório:

Tratados e leis de todo o mundo reconhecem a educação como um direito humano fundamental. Além disso, a educação transmite conhecimentos e habilidades que permitem às pessoas desenvolverem ao máximo seu potencial e, por isso, torna-se um catalisador para a realização de outros objetivos de desenvolvimento. (UNESCO, 2014, p. 22; grifo nosso) 
Localmente, pode-se dizer que o Brasil aderiu tardiamente ao projeto da Unesco. Isso aconteceu apenas em 2006, com o projeto "Todos pela Educação (2006-2022)", "um movimento da sociedade civil brasileira", cujo propósito é que "até 2022 todas as crianças e jovens tenham direito a educação básica de qualidade" ${ }^{\prime \prime}$. O projeto brasileiro não define claramente qual seu entendimento à noção de educação, embora revele pistas, implicitamente, da forma como a percebe. Para tanto, observam-se as cinco metas propostas:

Meta 1 - trata do atendimento a um direito básico: o acesso à Educação. Até o ano de 2022,98\% das crianças e jovens entre 4 e 17 anos devem estar matriculados e frequentando a escola.

Meta 2 - até 2010,80\% ou mais, e até 2022, 100\% das crianças deverão apresentar as habilidades básicas de leitura e escrita até o final da $2^{\text {a }}$ série ou $3^{\circ}$ ano do Ensino Fundamental.

Meta 3 - Até 2022, 70\% ou mais dos alunos terão aprendido o que é essencial para o seu ano.

Meta 4 - Até 2022, 95\% ou mais dos jovens brasileiros de 16 anos deverão ter completado o Ensino Fundamental, e $90 \%$ ou mais dos jovens brasileiros de 19 anos deverão ter completado o Ensino Médio.

Meta 5 - Até 2010, mantendo-se até 2022, o investimento público em Educação Básica deverá ser de $5 \%$ ou mais do Produto Interno Bruto (PIB). ${ }^{2}$

Pode-se perceber em ambos os projetos a noção de educação enquanto reprodutora de conteúdos, o que, conforme Morin (2009), é "o problema da educação e da pesquisa, que se encontram reduzidos a termos meramente quantitativos" (MORIN, 2009, p. 82). Embora as propostas tratem de transformar a realidade do sistema educacional, como se percebe, os caminhos adotados podem não ser adequados às propostas. Acredita-se que seja fundamental refletir sobre essa questão, já que "a educação, enquanto reflexo, retrata e reproduz a sociedade; mas também projeta a sociedade que se quer" (PIMENTA; ANASTASIOU, 2010, p. 97).

Assim, embora a sociedade em geral considere a importância da educação (CNI-IBOPE, 2010), percebe-se uma crença relativa quanto ao seu potencial de transformação social. Isso porque há de se identificar as "bases para perceber as diferenças entre os discursos e programas de ação que efetivamente traduzam a educação como possibilidade de desenvolvimento e de maior igualdade social e aqueles apenas a valorizam na retórica." (PIMENTA; ANASTASIOU, 2010, p. 96). Esse aspecto conduz a escolha da metodologia de análise do corpus selecionado, o discurso midiático. Wortmann (2001, p. 158), ao compreender as manifestações midiáticas acerca da educação, enfatiza a questão retórica: 
Temos examinado tais representações em filmes, revistas, propagandas, enciclopédias, programas educativos elaborados por fábricas, programas de prevenção de doenças conduzidos pelo Ministério da Saúde, entre outras tantas produções culturais que, mesmo sem estarem voltadas diretamente à escola, têm efeitos sobre as identidades dos sujeitos que lá estão e sobre as práticas que lá se instauram. (WORTMANN, 2001, p. 158)

Percebe-se, então, a relevância de situar a noção das representações elaboradas pela mídia a partir de propostas educacionais, uma vez que implicam diretamente na relação sujeito-mundo. Acredita-se que o olhar da semiolinguística de Charaudeau (2010, 2012), de base interativa e comunicacional, permita um olhar acurado à realidade apresentada na campanha midiática, que, por seus objetivos, vincula-se às propostas dos programas "Educação Para Todos" e "Todos pela Educação". Antes de prosseguir com a análise, apresentam-se as categorias que nortearão a análise do discurso.

A posição do analista acena a perspectiva do sujeito interpretante, cuja ação permite apenas indicar possíveis interpretativos acerca do corpus selecionado, já que a construção de sentido é imbricada à realidade de cada sujeito, diante de seus saberes (CHARAUDEAU, 2010). Ao tratar do discurso midiático, é importante ter em mente a dupla-lógica que orienta esse fazer: a econômica, cuja orientação remete à informação como produto, logo, passível de valoração e promoção de lucro; a outra lógica, simbólica, remete à participação na fundamentação da opinião pública (CHARAUDEAU, 2012).

O modelo de análise proposto por Charaudeau $(2010,2012)$ baseia-se no processo de troca entre as instâncias de produção e recepção. A primeira provém os elementos e a segunda seleciona-os e os põe em conexão, construindo sentido. Percebe-se, então, que o discurso é composto por estratégias, que se manifestam diante das escolhas de conteúdo, forma ou efeitos de sentido, que revelam, explícita ou implicitamente, a intencionalidade do comunicante. Tais escolhas baseiam-se no contrato de comunicação estabelecido a partir da relação estabelecida em uma situação de comunicação, que é tida como quadro de referência para o momento da interação, pois implica as restrições de espaço e tempo para que se deem as trocas discursivas. Nesse sentido, importa reconhecer que as condições da enunciação determinarão os aspectos discursivos adotados pelo ser que comunica.

Segundo Charaudeau (2012), refere-se às condições de enunciação o estabelecimento das identidades dos seres em interação. A instância da produção apresentará sua finalidade ou objetivo a partir das visadas comunicacionais, que podem ser de credibilidade, que visa o fazer-saber, 
ou de dramatização, cujo enfoque está no fazer-sentir, na mobilização pela afetividade. $\mathrm{O}$ propósito relaciona-se à abordagem do tema que estimula a produção discursiva e o dispositivo implica as circunstâncias materiais do trânsito dos discursos. São três os aspectos discursivos que podem ser observados na análise de textos da comunicação midiática: a locução, ou tomada da palavra, a relação que determina os papéis e orienta sua encenação e, a tematização, que é o tratamento do tema diante dos modos de intervenção (diretivo, de retomada, de continuidade) e organização discursiva (descritivo, narrativo, argumentativo) (CHARAUDEAU, 2012).

Com base nos dados acerca da situação atual do sistema educacional e da apresentação dos desafios da educação sob óticas mais amplas como as de Hall (1997) e Morin (2009), acredita-se que se tenha subsídios para refletir acerca da representação e (re)significação da educação a partir do objeto selecionado. Por meio da análise do discurso, acredita-se que o corpus que compõe o estudo apresentará elementos que conduzam à resposta do problema proposto.

\section{Procedimentos metodolóGicos}

Diante dos interesses deste estudo, elege-se como objeto de análise a campanha"A Educação precisa de Respostas", de 2013, elaborada pelo grupo de mídia gaúcho RBS e divulgada nos estados do Rio Grande do Sul (RS) e de Santa Catarina (SC). Trata-se de uma extensa proposta, iniciada em agosto de 2012, cuja característica principal está na estruturação multiplataforma sustentada pelos pilares editorial, institucional e publicitário. Refere-se a uma empreitada com expressivo engajamento social e reconhecimento público de sua relevância, a partir de moções em três cidades: Santa Maria (RS), Itajaí e Lages (SC).

A partir da extensão da campanha, faz-se necessária a limitação do material em análise, cuja seleção se deu a partir do critério de relevância simbólica, o qual se acredita mais evidente no pilar publicitário, diante dos ícones da campanha, os monstrinhos, e da síntese das ideias a que se pretende a campanha. Chega-se, então, ao corpus de pesquisa, que se restringe aos quatro anúncios veiculados nos jornais impressos do grupo RBS. Foram 235 publicações desses quatro diferentes textos publicitários. Devido aos elementos provenientes desses textos, acredita-se que atendam adequadamente às expectativas da investigação, cujo enfoque está na representação e (re)significação da noção de educação, a partir de uma apropriação midiática. 
A descrição do objeto e do corpus caracteriza a pesquisa aplicada, com abordagem qualitativa e objetivos exploratório e descritivo. Os procedimentos adotados para coleta de dados constituem-se de pesquisa documental, nos exemplares de revista selecionados, e pesquisa bibliográfica. Desta, emergem as perspectivas teórico-metodológicas adotadas, provenientes da interface entre as noções de cultura, educação e mídia. O percurso metodológico compreende a pesquisa bibliográfica, com o intuito de esclarecer os conceitos pertencentes às propostas teóricas mencionadas, cuja interface implicará a análise do corpus, diante das categorias principais da análise do discurso.

\section{DE QUAIS RESPOSTAS A EDUCAÇÃO PRECISA?}

A teoria semiolinguística propõe um caminho para identificação de possíveis interpretativos diante da produção de mensagens midiáticas à recepção. Das categorias propostas por Charaudeau $(2010,2012)$, apresentam-se algumas pistas que conduzem à representação da educação diante da (re)significação dos elementos que compõem o corpus selecionado.

O fator inicial da análise refere-se à contextualização da situação de comunicação. Percebe-se que a campanha lançada pelo grupo midiático RBS decorre dos movimentos da campanha internacional "Educação Para Todos" e da nacional "Todos pela Educação". O pilar publicitário sustenta a ação de veiculação de anúncios nos jornais impressos do grupo, os quais têm características específicas para veiculação. Os anúncios exploram as cores, e as expressões linguísticas complementam a proposta das imagens. $O$ foco desses produtos da comunicação da campanha é o jovem/adulto, visto que este é o público que se mantém leitor desse suporte midiático.

A promoção da campanha é do grupo RBS, em parceria com a Fundação Maurício Sirotsky, o qual faz menção em destaque nos anúncios, já que os logotipos dessas organizações aparecem em tamanho superior ao logotipo criado para a campanha. A partir da locução, o grupo assume a palavra e coloca-se à disposição da comunidade para "buscar as respostas que a educação precisa" e demonstra ser uma entidade preocupada com o progresso do país. Assim, incorpora a instância da recepção, que, embora seja anunciada a "cada um de nós que quer uma sociedade melhor" (conforme anúncio do Bicho-Papão), enfoca, nos anúncios analisados, a relevância da participação dos pais, como "agentes fiscalizadores", conforme anúncio da Bruxa, e para "acompanhar o desempenho dos filhos", enunciado presente no anúncio da Mula sem Cabeça. Os quatro anúncios que compõem o corpus são dispostos na Figura 1. 
Figura 1 - Corpus: os anúncios da campanha "A educação precisa de respostas" Da esquerda para direita: Mula sem Cabeça, Bruxa Malvada, Boi da Cara Preta. Abaixo: Bicho-Papão
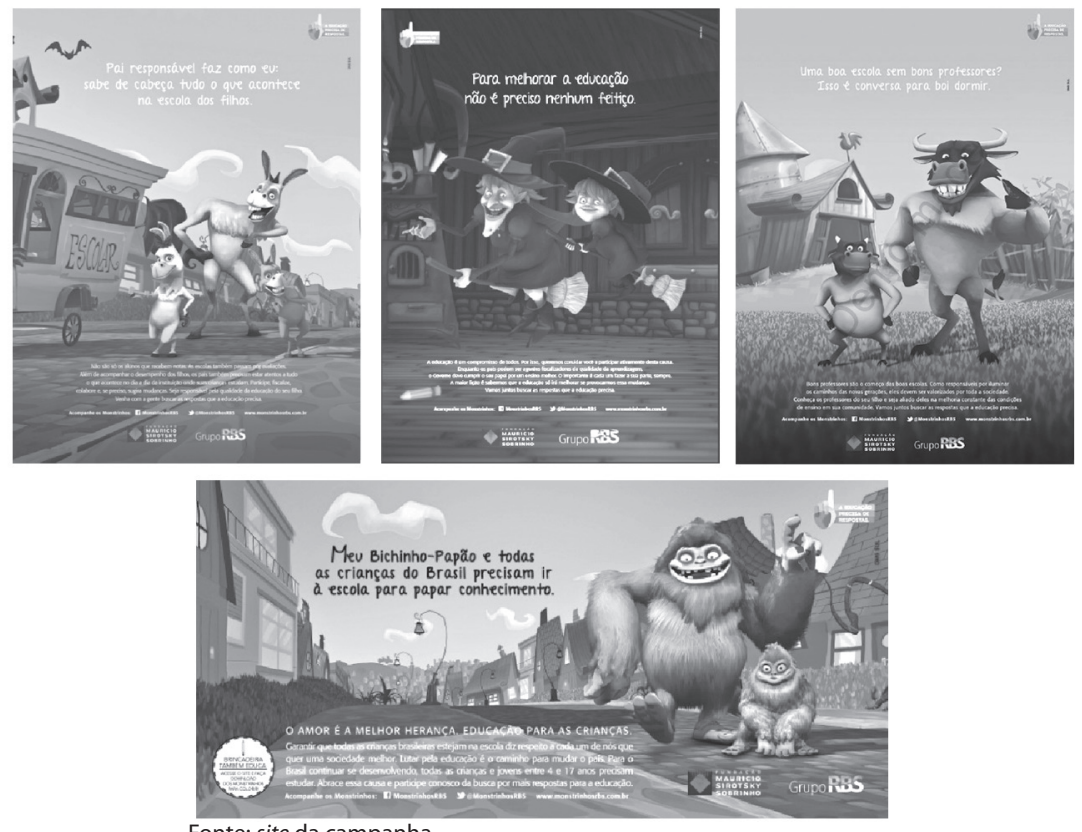

Fonte: site da campanha

A campanha, segundo divulgação do grupo midiático, objetiva mobilizar as comunidades do Rio Grande do Sul e de Santa Catarina em prol da melhoria da educação básica. Diante dos anúncios, associa-se essencialmente a visada de dramatização à abordagem, o que pode ser afirmado diante de alguns de seus elementos. A reutilização dos personagens "monstrinhos", que, em campanha anterior, de 2003, foram plenamente aceitos e causaram simpatia da audiência, é o mais evidente sinal de intenção de vinculação emocional com o público. As relações de poder, também relativas à visada de captação da atenção por meio das emoções, são perceptíveis no estímulo à fiscalização tanto das escolas quanto do poder público.

Embora não se possa estabelecer uma relação direta, tais aspectos foram refletidos em um levantamento feito pelo lbope, em novembro de 2013, no qual se buscava identificar os responsáveis pelo processo educacional. As alternativas disponíveis referem-se à ação do governo para a realização de projetos de educação. Salienta-se uma das questões, na qual a opção "disponibilizar mais verbas para investimento na área" teve $27 \%$ de adesão e a afirmação "Maior acompanhamento das famílias na rotina escolar dos 
seus filhos" teve 10\% de adesão. Evidenciam-se as escolhas da campanha em análise por privilegiar os pais no direcionamento das mensagens e por instigar a cobrança do poder público quanto ao investimento da educação.

A visada de credibilidade é também utilizada primordialmente pela elaboração da campanha em si, que visa demonstrar a responsabilidade social da empresa, além do uso de aspectos propostos pela campanha nacional para construir as narrativas encenadas pelos personagens principais. Tal visada é contemplada a partir do propósito ou tematização dos aspectos compartilhados. Embasada na proposta nacional, a estrutura da campanha "A Educação Precisa de Respostas" propõe uma intervenção de continuidade a partir de seu pilar publicitário. Os textos que compõem os anúncios são estruturados essencialmente pelo modo narrativo, no qual um narrador conta algo a um destinatário (CHARAUDEAU, 2010). Os trechos "Abrace essa causa e participe conosco da busca por mais respostas para a educação", no anúncio do Bicho-Papão, e "A educação é compromisso de todos. Por isso, queremos convidar você a participar ativamente desta causa", no anúncio da Bruxa Malvada, conduzem a essa percepção.

A escolha dos monstrinhos como narradores da campanha pode provocar diversas considerações, das quais se destacam algumas. A primeira alude à retomada de elementos de forte apelo emocional, que demonstram o interesse em promover uma aproximação afetiva e de credibilidade por meio daqueles que já são conhecidos e já contam com a simpatia do público. A segunda invoca o uso dos personagens para centralizar as mensagens aos pais, embora a campanha proponha-se a articular os vários atores sociais.

Uma terceira questão que pode inculcar a mente da instância de recepção envolve a seguinte afirmação no anúncio da Bruxa: "A maior lição é sabermos que a educação só irá melhorar se provocarmos essa mudança". Seria adequado remeter à noção de mudança a partir da reutilização de uma campanha, mesmo que ela tenha atendido plenamente as expectativas do grupo midiático em um momento anterior? Ao se considerar que "é preciso estabelecer uma perspectiva no ambiente escolar, modificando os discursos e as práticas lineares que reduzem a aprendizagem a um saber extenso e cumulativo que impede a percepção do complexo" (RIBEIRO, 2009, p. 43), é relevante dar atenção a essa forma de representação da educação.

Quanto aos cenários nos quais os personagens encenam seus discursos, estes estão associados ao espaço doméstico como principal lócus da educação. A disposição de um caminho a ser percorrido pelos personagens está presente nos quatro anúncios, o que permite que se considere que a ação dos pais está centrada no levar os filhos à escola. O anúncio da Mula 
Sem Cabeça inclui uma charrete como transporte e apenas o anúncio da Bruxa contempla elementos que remetem à construção do conhecimento, como livros e lápis. Nos textos, as referências à escola estão relacionadas à responsabilidade de "iluminar os caminhos das novas gerações"e que, por isso, os professores "devem ser valorizados por toda a sociedade" (anúncio do Boi da Cara Preta). Diante desses aspectos, pode-se refletir sobre a valorização do trabalho docente proposta pela campanha, assim como as falhas para inclusão dos diferentes atores sociais ao processo de melhoria da educação básica.

Ao se considerar a proposta de Hall (1997), que contempla o olhar à cultura para a construção de significados e permanente (re)significação dos saberes adquiridos, cabe observar, ainda, o cenário onde se dá a encenação dos anúncios. Pode-se considerar que os anúncios do Boi da Cara Preta e da Bruxa Malvada valorizam os aspectos culturais relacionados ao meio de onde se originam os sujeitos, que envolve o olhar local acerca do mundo, enquanto a Mula Sem Cabeça e o Bicho-Papão compartilham cenários semelhantes, que podem ser relacionados à homogeneização proveniente da mundialização. Nesse sentido, a proposta da campanha é interessante, pois contempla a diversidade da contemporaneidade, que comunga do local e do global.

Há ainda alguns aspectos que assumem relevância quando se propõe o olhar da representação da educação a partir de anúncios, cuja motivação provém de uma animação. A Mula Sem Cabeça, por exemplo, é colocada como modelo para os pais:"Pai responsável faz como eu: sabe de cabeça tudo o que acontece na escola dos filhos". Propõe, na sequência, que ser responsável é sinônimo de participar, fiscalizar, colaborar e sugerir mudanças. $O$ enfoque desse anúncio está no "ficar de olho" na avaliação de desempenho da escola e do aluno.

Por fim, salienta-se a expressão"papar conhecimento", cunhada pelo Bicho-Papão. Papar é sinônimo de comer, uma ação orgânica e natural do ser humano. Como figura de linguagem, desconsidera o processo reflexivo de construção do conhecimento e dá relevo ao conhecimento enciclopédico, decorado, desconexo da realidade, tanto do aluno, quanto da sociedade atual, que, conforme Hall (2003), é tomada por conceitos de tempo e espaço que alteram o estado das coisas constantemente.

Diante dos elementos mencionados na análise, pode-se indicar alguns caminhos à representação da educação pela instância midiática, já que a apropriação e (re)significação desses elementos são relacionados à experiência do sujeito interpretante. Acredita-se que a função essencial de uma reflexão como a desta proposta seja a de promover indagações quanto aos discursos que são constantemente repetidos e repercutidos, por vezes 
com roupagens diferentes, mas que essencialmente reproduzem e perpetuam modelos que talvez não sejam mais adequados à realidade vigente. Nesse sentido, segue-se com a apresentação de alguns possíveis interpretativos.

\section{POSSÍVEIS INTERPRETATIVOS: PISTAS PARA ALGUMAS CONSIDERAÇÕES}

Os dados apresentados pelos relatórios mencionados no texto mostram a realidade do sistema educacional e apontam as medidas tomadas frente à evolução da educação. Assim, é importante salientar a relevância da campanha conduzida pelo grupo midiático RBS, pois congrega com as propostas da sociedade civil brasileira a reflexão sobre os papéis de cada ator social no desenvolvimento de políticas educacionais e também das atitudes que mobilizam mudanças no comportamento cidadão. Confirma-se, porém, que o fazer midiático cristaliza os elementos propostos pela temática da educação em vez de problematizá-los. É o fazer pela lógica mercadológica em detrimento da ação formadora de opinião crítica.

Simultaneamente, é importante referenciar os projetos "Todos pela Educação" e "Educação para Todos", que propagam uma perspectiva de transmissão de conhecimento ao entendimento da educação, enfatizando algumas disciplinas e desconsiderando outras, aplicando padrões que não estão adequados à diversidade cultural que caracteriza os sujeitos na contemporaneidade. O paradoxo desse tempo é o desafio que precisa estar em conjunção às práticas educacionais (HALL, 1997). Caso contrário, os aspectos negativos referenciados por Bauman (2007) tendem a manter-se, e a realidade tende a permanecer mergulhada nos problemas sociais presentes nos relatórios, como a segregação diante de questões financeiras, que limitam as possibilidades de transformação da realidade de muitas crianças e jovens (UNESCO, 2014).

Dessa maneira, cabe a ponderação de Pimenta e Anastasiou (2010) acerca da atenção às diferenças entre projetos/programas que visam de fato uma ação transformadora da educação e aqueles que se projetam apenas na retórica. Não se propõe, neste espaço, analisar as campanhas em níveis internacionais ou nacionais, mas considerar o recorte especificado do corpus. Assim, ao considerar o pilar publicitário da campanha, pode-se sugerir que, apesar do esforço do grupo midiático em promover essa ação vinculada a uma factual responsabilidade social, ela é parcialmente percebida, posto que, diante da análise, evidenciam-se as contradições em vários aspectos, como a ação dos atores ou mesmo a seleção dos personagens e, ainda, o aspecto efetivamente reflexivo acerca do sistema educacional, que fica em plano secundário. 
Cabe, então, questionar qual é de fato a educação que se quer para a sociedade. Conforme propõe Carnoy (2002), o enfoque está nas avaliações quantitativas, que selecionam e posicionam os sujeitos no mundo diante de suas habilidades, visto que elas desenvolvem-se diante das possibilidades que o meio lhes oferece. Ou, talvez, conforme o olhar de Hall (1997) e Morin (2009), que, embora não compartilhem da mesma linha teórica, promovem um olhar abrangente à educação, que pode ser plenamente conectado, uma vez que vão além da segregação disciplinar e consideram a complexidade que envolve a cultura mundializada, que converge local e global, sem exterminar um ou outro, mas transformando-se permanentemente. Se se concorda com Morin (2009), que há a necessidade de uma reforma no pensamento, talvez seja adequado rever a forma disciplinar, unilateral e fiscalizadora na qual a educação é representada nos anúncios da campanha analisada.

Outro possível interpretativo decorrente da campanha "A Educação Precisa de Respostas" implica a posição de Pimenta e Anastasiou (2010) acerca do desaparecimento da escola transmissora de conteúdos, visto sua ineficiência em comparação com outros agentes, como a mídia, por exemplo. Se se concorda com esse apontamento, então é fundamental rever o sentido que se produz. Aceita-se que falta na abordagem publicitária uma vinculação entre as ações de alunos, pais, professores, sociedade, governo, em suma, de todos os atores sociais em interação, já que a campanha demarca responsabilidades de alguns deles, em vez de contemplá-las e integrá-las.

Por fim, salienta-se que o objeto é bastante rico como fonte de dados para análise da relação mídia-educação, uma vez que sua proposta multimidiática promove uma vasta gama de elementos simbólicos que permitem a indicação dos rumos que vêm sendo traçados pela educação. Haja vista que várias são as plataformas que compõem a campanha, algumas com múltiplas formas de interação, como internet, ações junto às escolas e comunidades, ou mesmo ações unilaterais, como a reprodução de peças em meios tradicionais, como TV, rádio e jornal, de onde advêm o corpus deste estudo, elas permitem importantes (e mesmo preocupantes) conexões sobre a (re)significação proposta pela campanha e as representações que inferem a realidade.

Diante dessas considerações, acredita-se que os objetivos propostos foram atendidos, o problema de pesquisa foi respondido e a hipótese proposta foi confirmada, uma vez que a análise contempla os elementos que são utilizados na representação da educação, como os personagens, algumas expressões e os sentidos produzidos diante da análise dos fragmentos de texto apresentados. A conjunção desses aspectos constrói uma representação da educação enquanto transmissora de saberes e habilidades, na qual os pais e o governo têm papel-chave e a ação dos professores é secundária. 
"EDUCATION NEEDS ANSWERS" OR ARE THE ANSWERS IN EDUCATION? REPRESENTATION AND (RE)SIGNIFICATION IN THE RBS MONSTERS' CAMPAIGN

ABSTRACT: Reflecting on education implies getting closer to the realities constructed by subjects in their interactions. Media action, which produces and relays information stemming from the events of everyday life, are related to this issue. These perspectives come together as both are evident in the formation of citizen opinion. Against this background and using the campaign "Education needs Answers", this study proposes to analyze media discourse on education with a view to understanding how it is represented and (re) signified. The underlying theoretical framework is based on Hall (1997), Morin (2009) and Charaudeau (2012). The main results point to the fact that the campaign has social relevance in that it awakens interest in the subject, but only does so partially in the face of the challenges of present day education.

KEY WORDS: Media. Education. The RBS campaign. Discourse analysis.

\section{¿"LA EDUCACIÓN NECESITA RESPUESTAS" O LAS RESPUESTAS ESTÁN EN LA EDUCACIÓN? REPRESENTACIÓN Y (RE)SIGNIFICACIÓN DE LA CAMPAÑA DE LOS MONSTRICOS DE LA RBS}

RESUMEN: Pensar la educación implica la aproximación con las realidades construidas por los individuos en sus interacciones. Relacionada a este aspeto, está la acción mediática, que produce y repercute informaciones a partir de los sucesos de la cotidianidad. Esas perspectivas se unen, ya que ambas asumen evidencia en la formación de la opinión ciudadana. En este contexto, a partir de la campaña “La educación necesita respuestas", se propone el análisis del discurso de los medios sobre la educación con el fin de percibir cómo esta es representada y (re) significada. El marco teórico consta de Hall (1997), Morin (2009) y Charaudeau (2012). Como principales resultados, se cree que la campaña tenga relevancia social, por despertar el interés por el tema, pero lo hace de forma parcial delante de los desafíos de la educación en la contemporaneidad.

Palabras claves: Medios de comunicación. Educación. Campaña de la RBS. Análisis del discurso.

\section{NOTAS}

1. Disponível em: <http://www.todospelaeducacao.org.br/institucional/quem-somos/>. Acesso em: 3 mar. 2014.

2. Disponível em: <http://www.todospelaeducacao.org.br/institucional/as-5-metas/>. Acesso em: 3 mar. 2014. 


\section{REFERÊNCIAS}

BAUMAN, Z. Tempos líquidos. Rio de Janeiro: Jorge Zahar, 2007.

.Vivemos o fim do futuro. Disponível em: <http://fronteiras.com/canalfronteiras/entrevistas/?16\%2C188>. Acesso em: 21 fev. 2014.

CALDAS, G. Mídia, escola e leitura crítica do mundo. Revista Educação \& Sociedade, São Paulo, v. 27, n. 94, p. 117-130, jan./abr. 2006.

CARNOY, M. Mundialização e reforma da educação: o que os planejadores devem saber. Brasília: Unesco, 2002.

CHARAUDEAU, P. Discurso das mídias. 2. ed. São Paulo: Contexto, 2012.

. Linguagem e discurso: modos de organização. 2. ed. São Paulo: Contexto, 2010.

CONFEDERAÇÃO NACIONAL DA INDÚSTRIA. Pesquisa CNI-IBOPE: Retratos da Sociedade Brasileira: educação. Brasília: CNI, 2010. Disponível em: <http://www.cni.org. br/portal/data/files/00/FF8080812AA3DBC6012AA45A0484570B/cni_ibope_educacao_agosto2010_web.pdf>. Acesso em: 3 mar. 2014.

HALL, S. A centralidade da cultura: notas sobre as revoluções culturais do nosso tempo. Educação \& Realidade, Porto Alegre, v. 22, n. 2, p. 15-46, jul./dez. 1997.

. A identidade cultural na pós-modernidade. Rio de Janeiro: DP\&A, 2006.

. Pensando a Diáspora: reflexões sobre a terra no exterior. In: HALL, S. Da Diáspora. Minas Gerais: Ed. UFMG, 2003. p. 25-50.

INSTITUTO NACIONAL DE ESTUDOS E PESQUISAS EDUCACIONAIS ANÍSIOTEIXEIRA. Censo da Educação Básica, Resumo Técnico. Brasília: INEP, 2012. Disponível em: <http:// portal.inep.gov.br/resumos-tecnicos>. Acesso em: 3 mar. 2014.

LIPOVETSKY, G. A sociedade da decepção. Barueri: Manole, 2007.

MORIN, E. Educação e complexidade: os sete saberes e outros ensaios. 5. ed. São Paulo: Cortez, 2009.

PIMENTA, S. G.; ANASTASIOU, L. G. C. Educação, identidade e profissão docente. In: . Docência no ensino superior. 4. ed. São Paulo: Cortez, 2010. p. 95-136.

RBS, G.; SOBRINHO, F. M. S. Relatório de Resultados da Campanha:"A educação precisa de respostas" Disponível em: <http://www.clicrbs.com.br/pdf/15995418.pdf>. Acesso em: 28 jan. 2014.

RIBEIRO, R. R. Escola, Mídia e comunicação: sistemas complexos. Inter-Ação: Revista da Faculdade de Educação, Goiás, v. 34, n. 1, p. 37-50, jan./jun. 2009.

SENNETT, R. A corrosão do caráter: consequências pessoais do trabalho no novo capitalismo. 14. ed. Rio de Janeiro: Record, 2009.

TODOS PELA EDUCAÇÃO. Pesquisa sobre responsabilização na educação. Disponível em: <http://www.todospelaeducacao.org.br/biblioteca/1484/apresentacao-resultados-pesquisa-sobre-responsabilizacao-na-educacao/>. Acesso em: 30 mar. 2014. 
UNESCO. Relatório de Monitoramento Global de EPT. Ensinar e aprender: alcançar a qualidade para todos. Unesco, 2014. Disponível em: <http://unesdoc.unesco.org/ images/0022/002256/225654por.pdf>. Acesso em: 3 mar. 2014.

WORTMANN, M. L. C. O uso do termo representação na educação em ciências e nos estudos culturais. Revista Pro-Posições, v. 12, n. 1, v. 34, p. 151-161, mar. 2001.

Gislene Feiten Haubrich é mestranda em Processos e Manifestações Culturais (Feevale), especialista em Comunicação Estratégica e Branding (UMayor e Feevale) e graduada em Comunicação Social.

E-mail: gisleneh@gmail.com

ERnani Cesar de Freitas é doutor em Letras (PUCRS), com pós-doutorado em Linguística Aplicada e Estudos da Linguagem (PUCSP/ LAEL), e professor permanente do Mestrado em Processos e Manifestações Culturais (Feevale).

E-mail: ernanic@feevale.br 